\title{
Combined Effect of Preparation Method and Compression on the Physical Stability and Dissolution Behavior of Melt-Quenched Amorphous Celecoxib
}

Kārlis Bērziņša, Sara J. Fraser-Miller ${ }^{\mathrm{a}}$, Rong Di ${ }^{\mathrm{b}}$, Jingwen Liu ${ }^{\mathrm{b}}$, Leena Peltonen ${ }^{\mathrm{c}}$, Clare J. Strachan ${ }^{\mathrm{c}}$, Thomas Rades ${ }^{\mathrm{b}}$, Keith C. Gordon ${ }^{\mathrm{a}^{*}}$

aThe Dodd-Walls Centre for Photonic and Quantum Technologies, Department of Chemistry, University of Otago, Dunedin 9016, New Zealand

${ }^{b}$ Department of Pharmacy, Faculty of Health and Medical Sciences, University of Copenhagen, Copenhagen 2100, Denmark

'Drug Research Program, Division of Pharmaceutical Chemistry and Technology, Faculty of Pharmacy, University of Helsinki, Helsinki 00014, Finland

*Corresponding author

\section{Supporting information}

Table S1. Overview of the design of experiments (DOE).

\begin{tabular}{|c|c|c|c|c|}
\hline No. & Cooling-rate, ${ }^{\circ} \mathrm{C} / \mathrm{min}$ & Compression pressure, $\mathrm{MPa}$ & Dwell time, $\mathrm{s}$ & Number of samples \\
\hline 1 & \multirow{6}{*}{$>100{ }^{\circ} \mathrm{C} / \mathrm{min}$ (fast) } & 0 & 0 & 2 \\
\hline 2 & & 125 & $0^{*}$ & 2 \\
\hline 3 & & 125 & 60 & 2 \\
\hline 4 & & 250 & 30 & 3 \\
\hline 5 & & 500 & $0^{*}$ & 2 \\
\hline 6 & & 500 & 60 & 2 \\
\hline 7 & \multirow{6}{*}{$25-30^{\circ} \mathrm{C} / \mathrm{min}$ (slow) } & 0 & 0 & 2 \\
\hline 8 & & 125 & $0^{*}$ & 2 \\
\hline 9 & & 125 & 60 & 2 \\
\hline 10 & & 250 & 30 & 3 \\
\hline 11 & & 500 & $0^{*}$ & 2 \\
\hline 12 & & 500 & 60 & 2 \\
\hline
\end{tabular}

"The dwell time was limited to the minimum. 


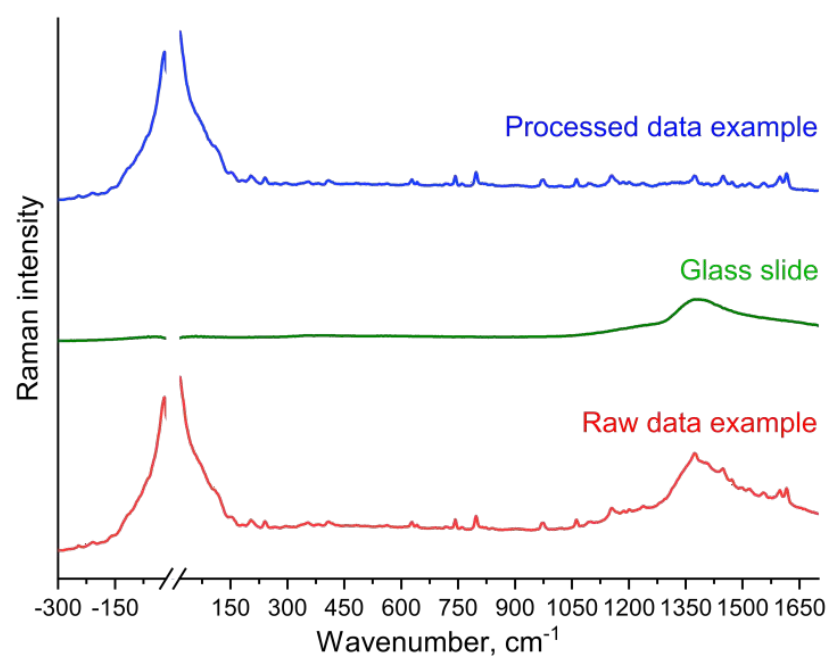

Figure S1. Typical Raman spectra of a glass slide and freshly prepared amorphous celecoxib control samples (raw and processed data).
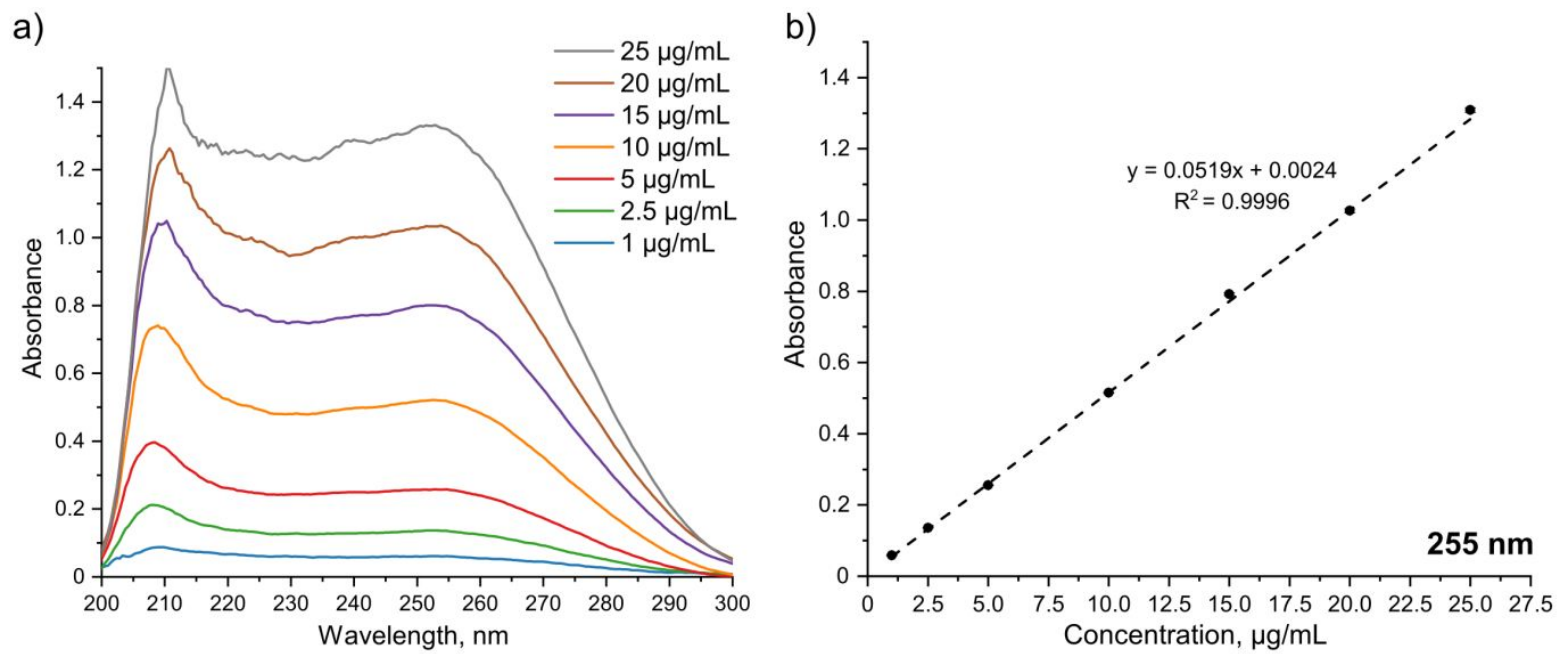

Figure S2. (a) Representative UV/Vis spectra of various celecoxib calibration samples $(1-25 \mu \mathrm{g} / \mathrm{mL})$ and (b) the respective calibration curve at $255 \mathrm{~nm}$ (mean \pm standard deviation; $\mathrm{n}=5$; error bars are smaller than the used symbol size). 
a)

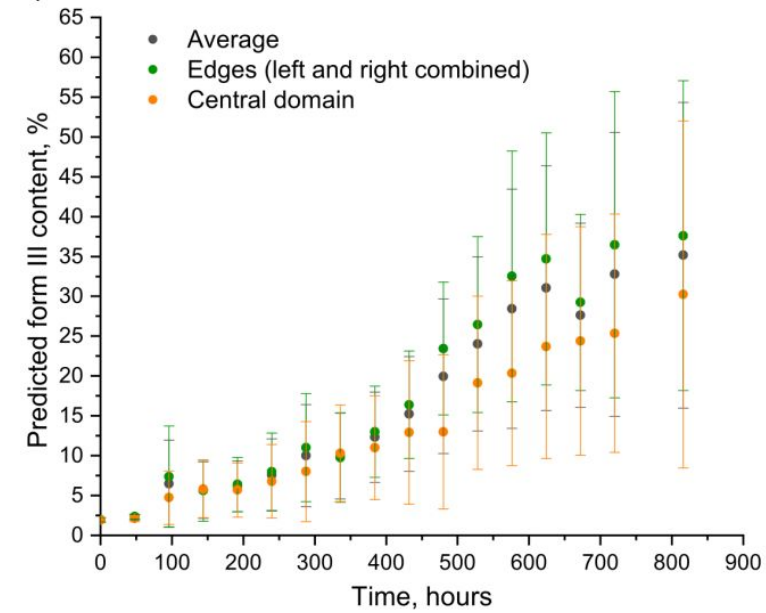

b)

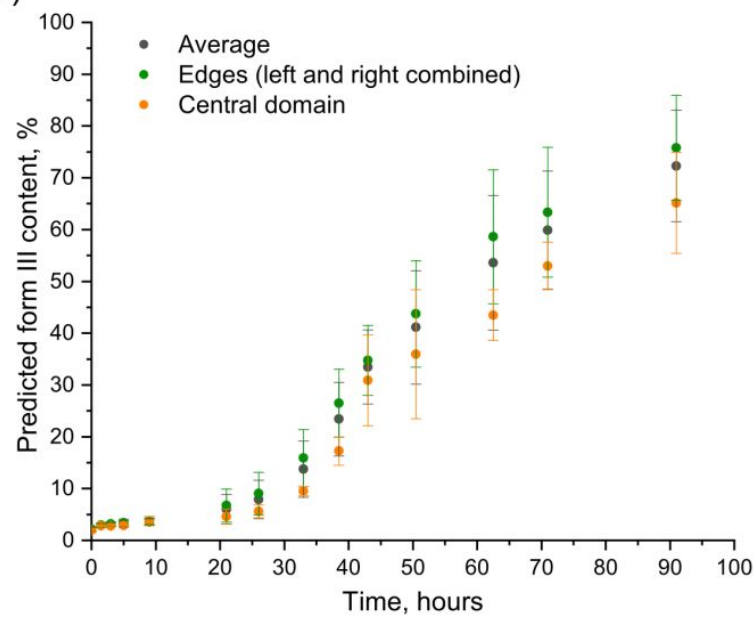

Figure S3. Combined crystallization profiles of all the fast melt-quenched amorphous celecoxib samples $(\mathrm{n}=3)$ compressed using $250 \mathrm{MPa}$ pressure and $30 \mathrm{~s}$ dwell time showing spatial crystallization tendencies when stored at $\sim 20{ }^{\circ} \mathrm{C}$ and (a) $<5 \%$ or (b) $97 \% \mathrm{RH}$ (mean \pm standard deviation; $\mathrm{n}_{\text {average }}=9$, $\mathrm{n}_{\text {edges }}=6$ and $\mathrm{n}_{\text {central domain }}=3$ ).
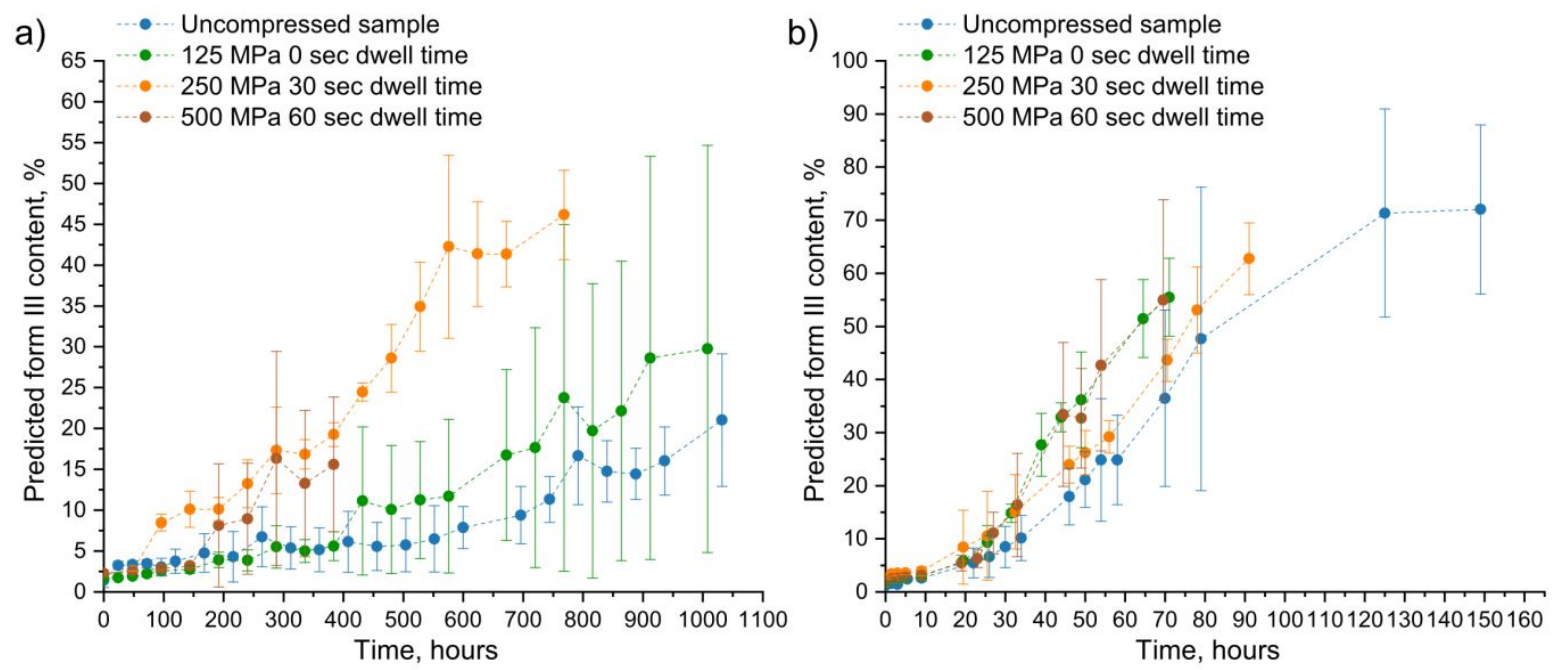

Figure S4. Representative crystallization profiles of individual uncompressed/compressed amorphous celecoxib samples (slow melt-quench) stored at $\sim 20{ }^{\circ} \mathrm{C}$ and (a) $<5 \%$ or (b) $97 \% \mathrm{RH}$ (mean \pm standard deviation; $n=3$ ). The lines are drawn to assist in visualizing the trends. 
a)

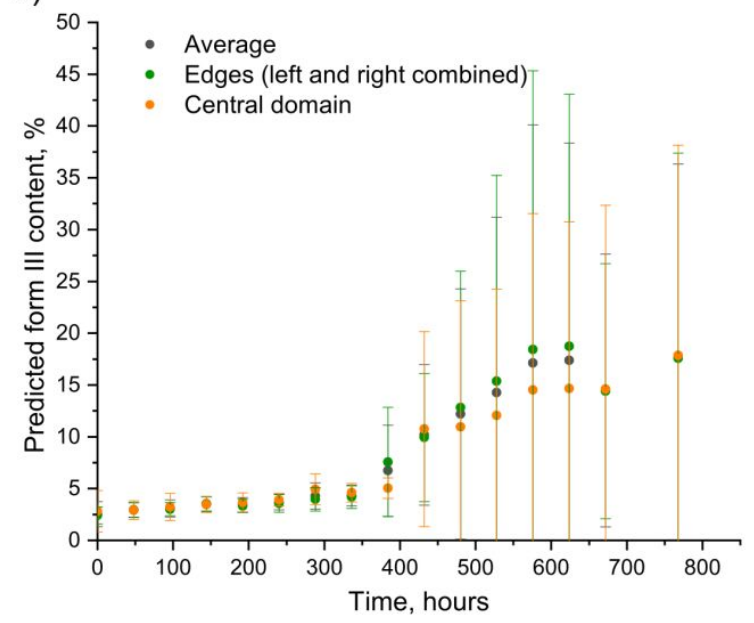

b)

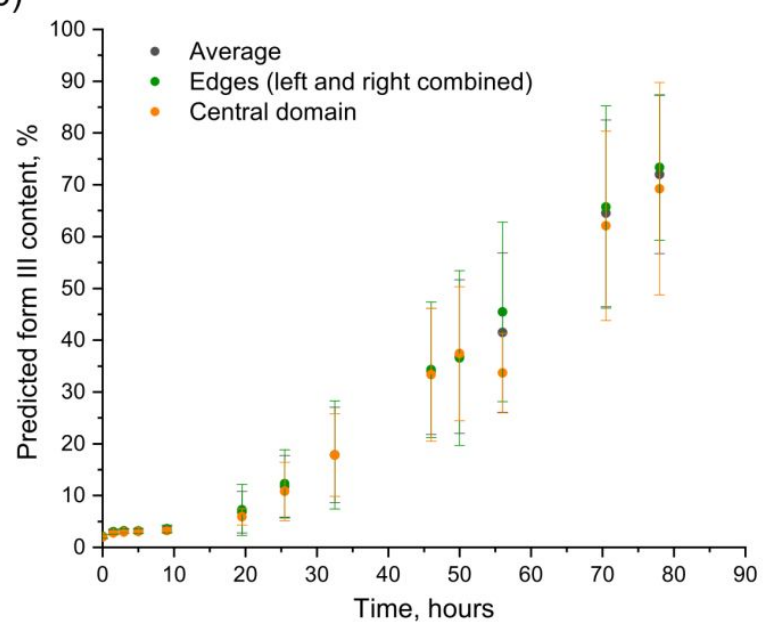

Figure S5. Combined crystallization profiles of all the slow melt-quenched amorphous celecoxib samples $(\mathrm{n}=3)$ compressed using $250 \mathrm{MPa}$ pressure and $30 \mathrm{~s}$ dwell time showing some spatial crystallization tendencies when stored at $\sim 20{ }^{\circ} \mathrm{C}$ and (a) $<5 \%$ or (b) $97 \% \mathrm{RH}$ (mean \pm standard deviation; $\mathrm{n}_{\text {average }}=9, \mathrm{n}_{\text {edges }}=6$ and $\mathrm{n}_{\text {central domain }}=3$ ).
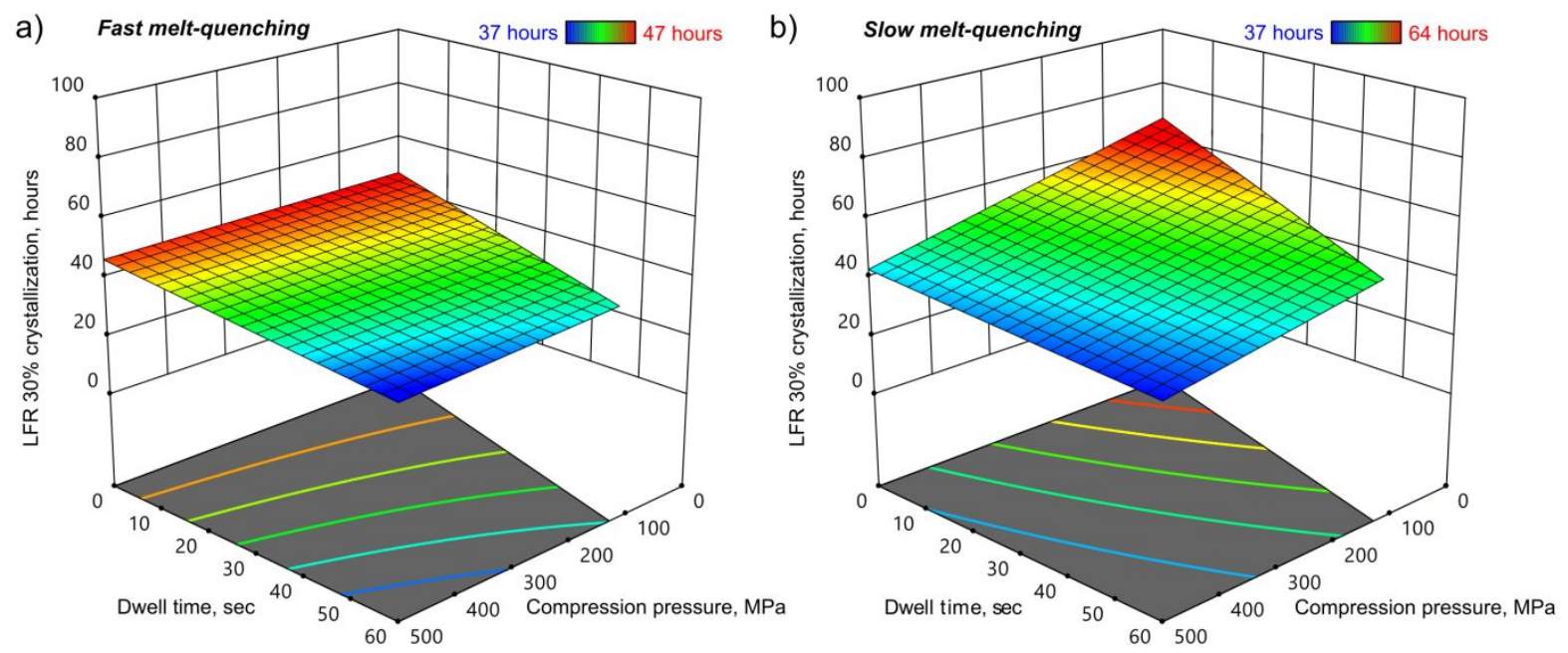

Figure S6. The LFR 30\% crystallization response surface plots for amorphous celecoxib samples procured via (a) fast or (b) slow melt-quenching and that were compressed using a combination of different compression parameters and stored at $\sim 20^{\circ} \mathrm{C} ; 97 \% \mathrm{RH}$. 


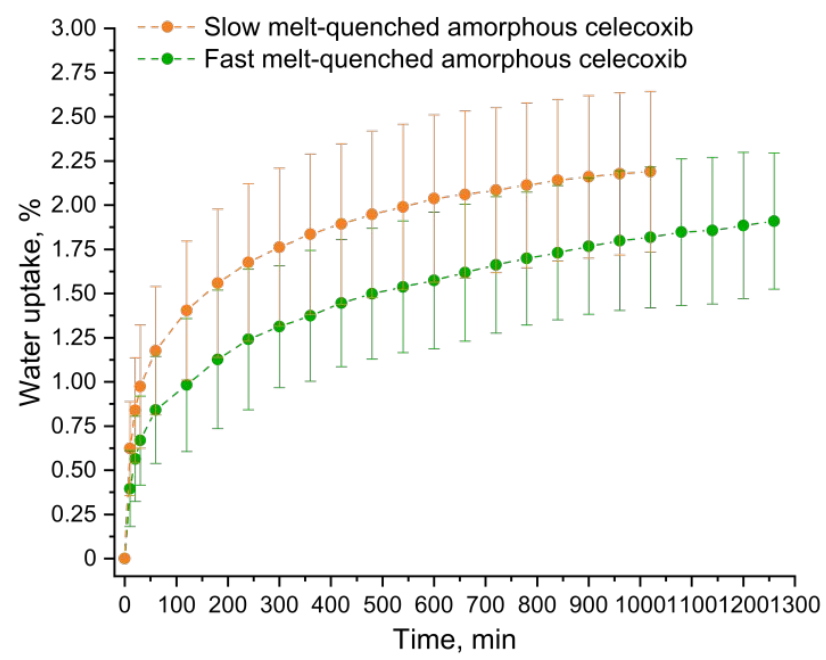

Figure S7. Water sorption profiles of in-situ differently melt-quenched amorphous celecoxib samples kept under $20^{\circ} \mathrm{C}$ and $97 \% \mathrm{RH}$ (mean \pm standard deviation; $\mathrm{n}=3$ ). For clarity, only several common time-points were chosen to draw the plots. The lines are drawn to assist in visualizing the trends.

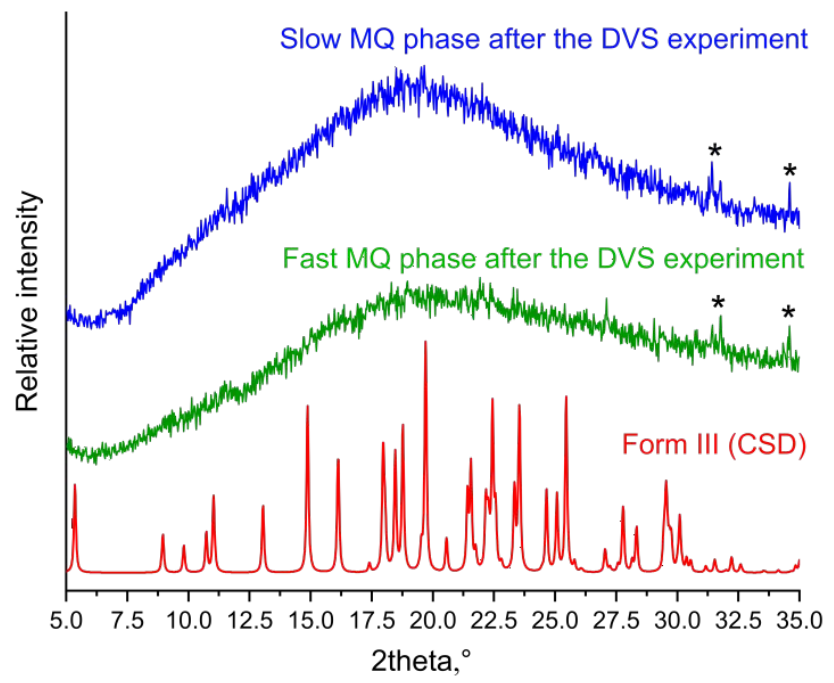

Figure S8. Representative PXRD patterns of celecoxib form III (from Cambridge Structural Database) and amorphous celecoxib samples (procured either with fast or slow melt-quenching) after the water sorption experiments. Asterisks $(*)$ denote peaks attributed to the sample holder. 


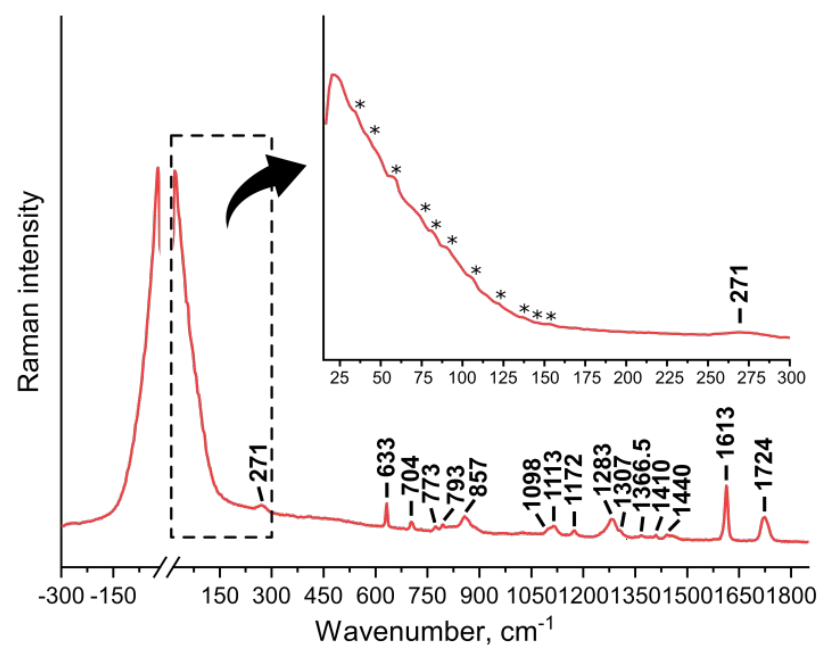

Figure S9. Representative Raman spectrum of a glass cover for the dissolution flow-through cell. Asterisks $(*)$ denote rotational sidebands of air that are detected when analyte exhibits weak LFR signal. 
a)

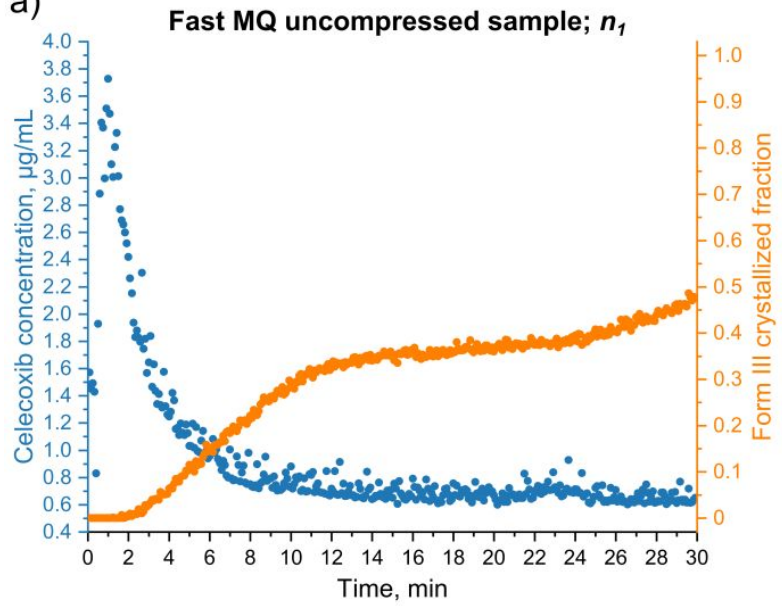

b)
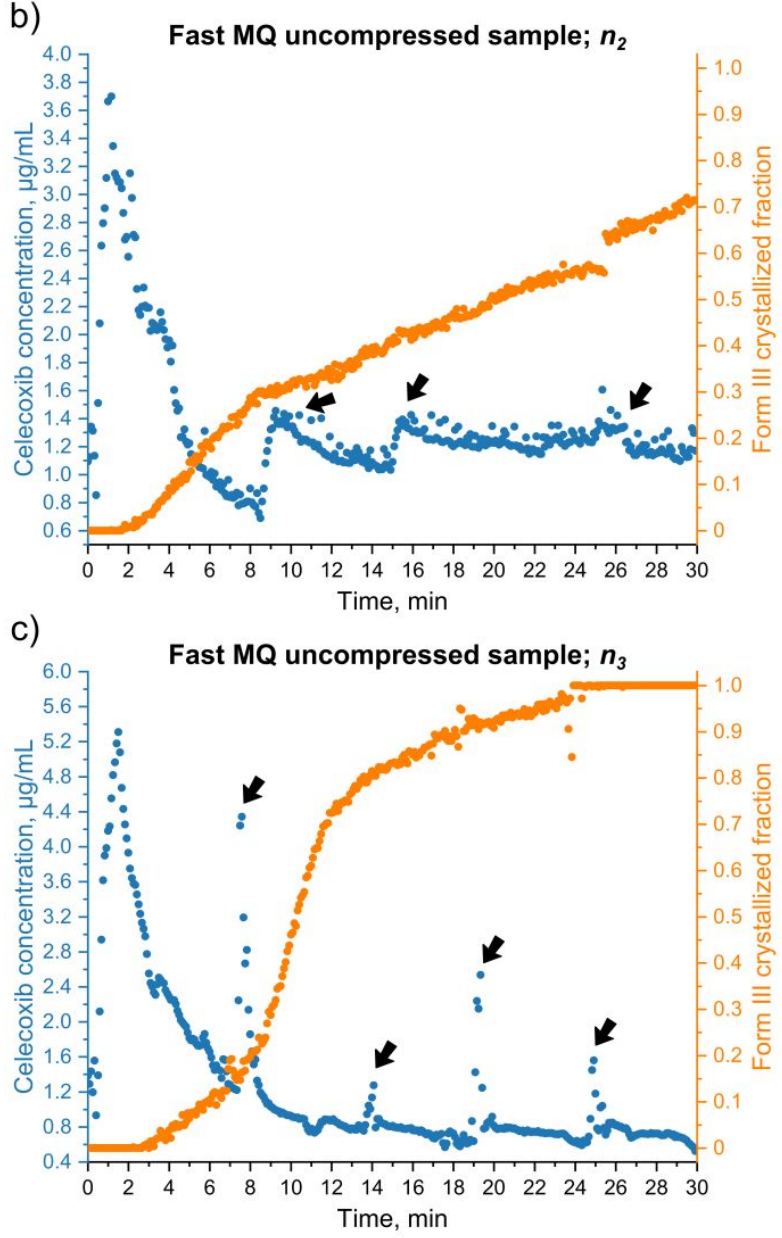

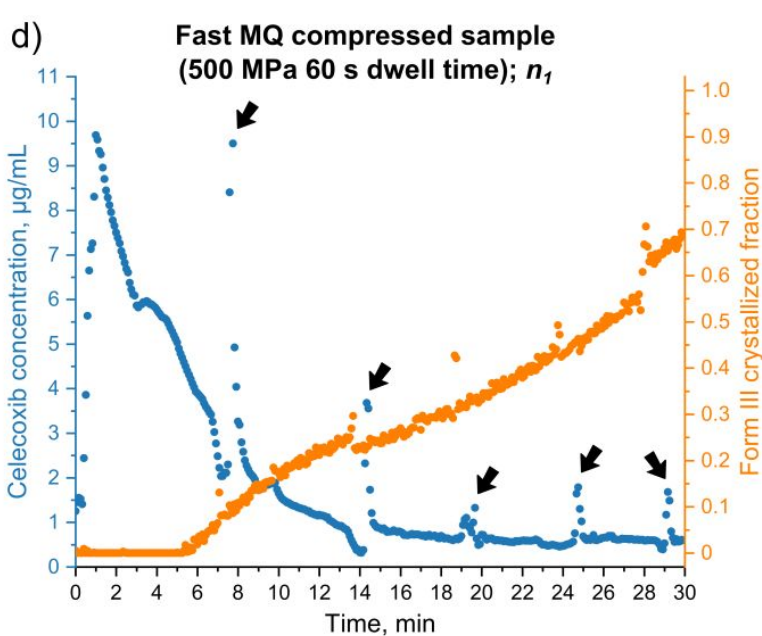

e)

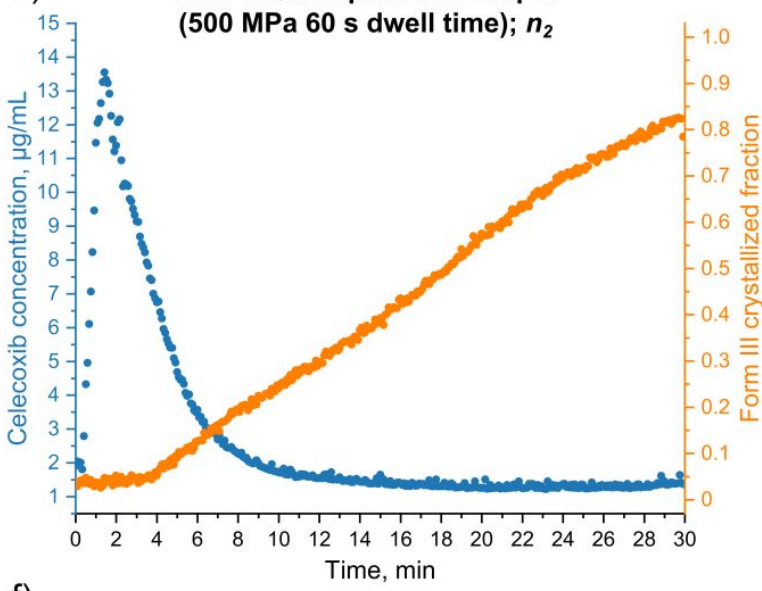

f)

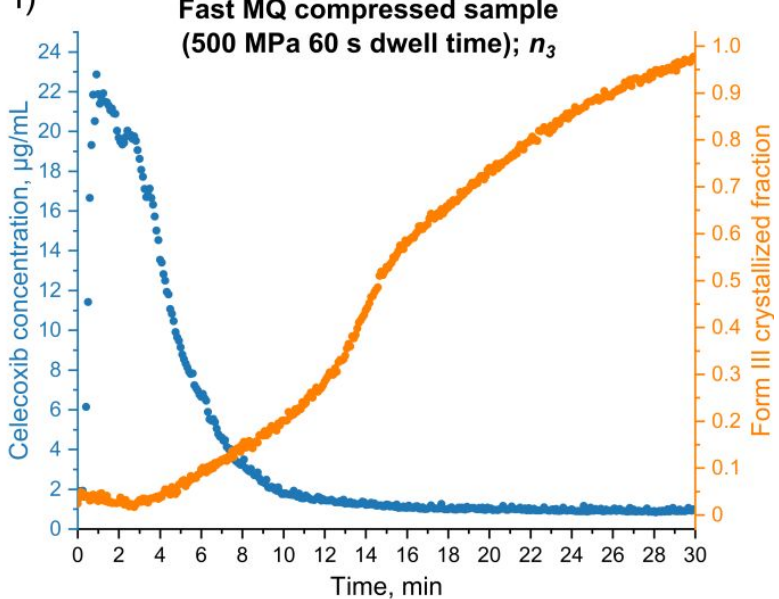

Figure S10. Dissolution profiles and MCR crystallization curves of component 2 (celecoxib form III) for fast melt-quenched (a-c) uncompressed and (d-f) compressed samples. Arrows denote artefacts due to the occasional air bubbles that were observed visually and distorted the LFR signal as well as manifested as a baseline in the UV/Vis spectra. Data from these regions were subtracted (not used) to determine the area under the dissolution curve. 
a)

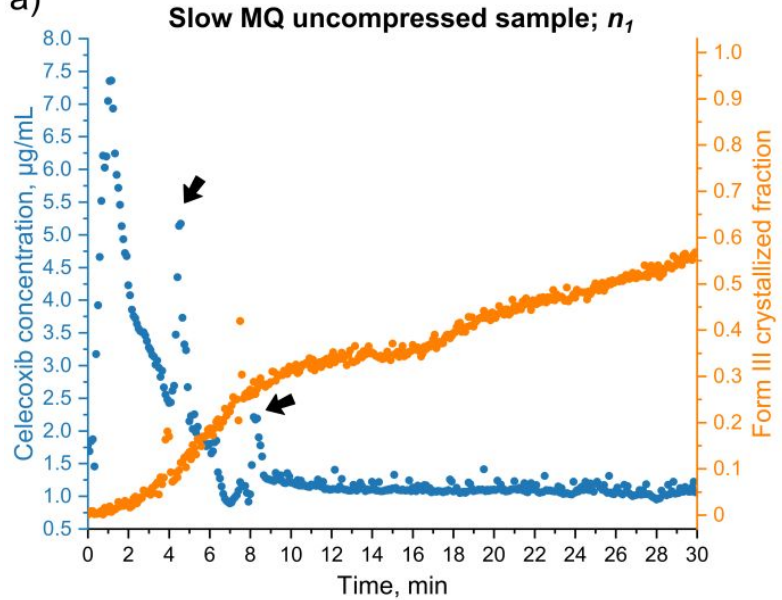

b)

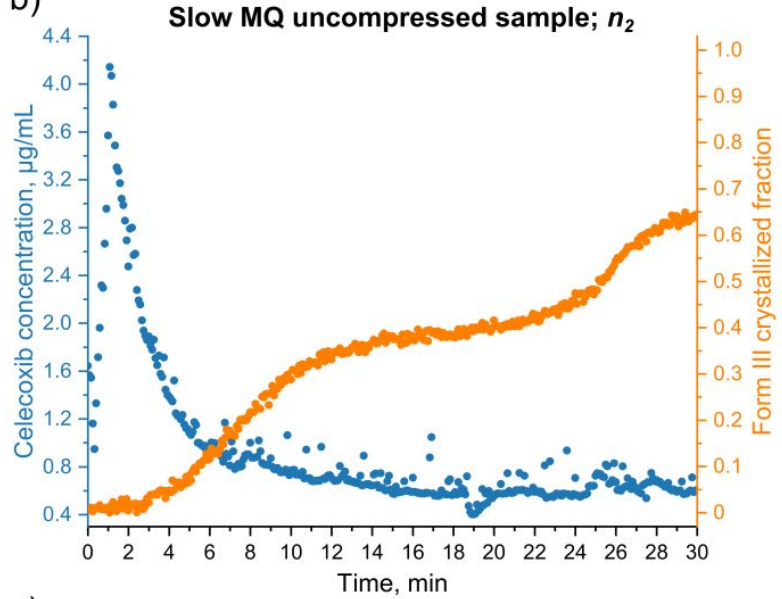

c)

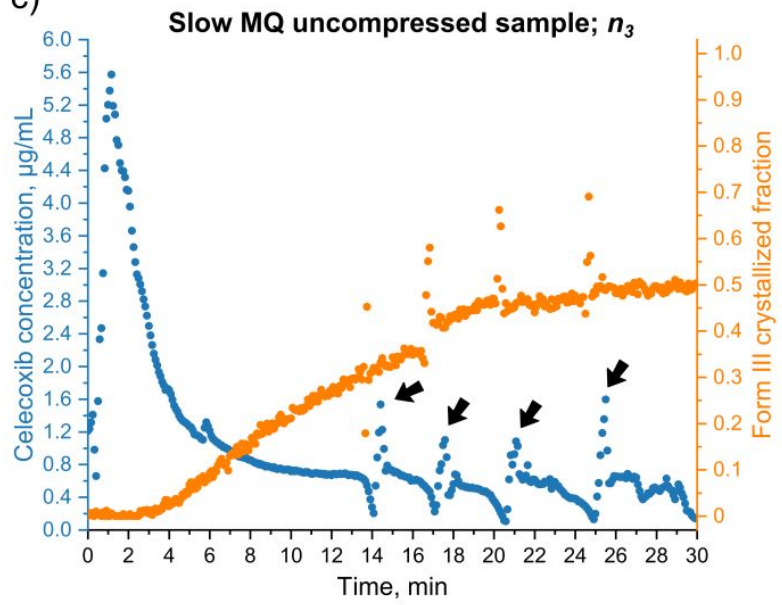

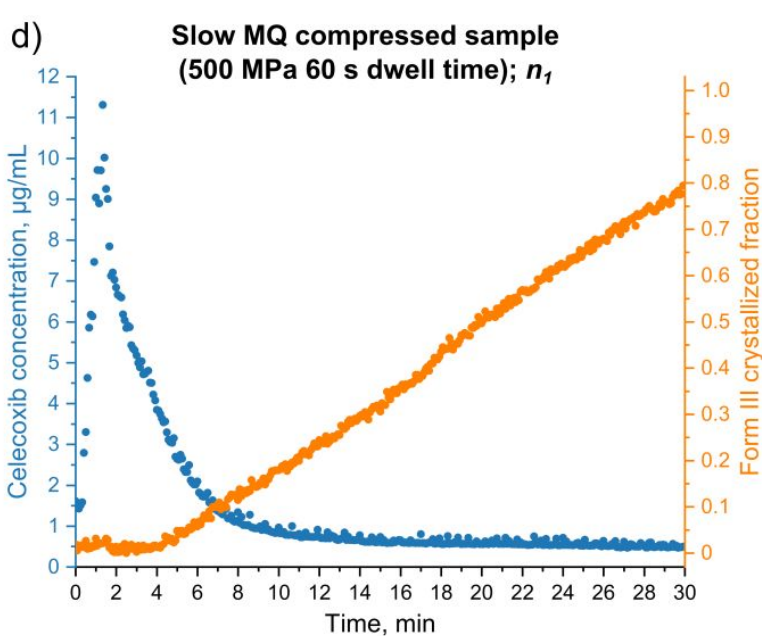

e)

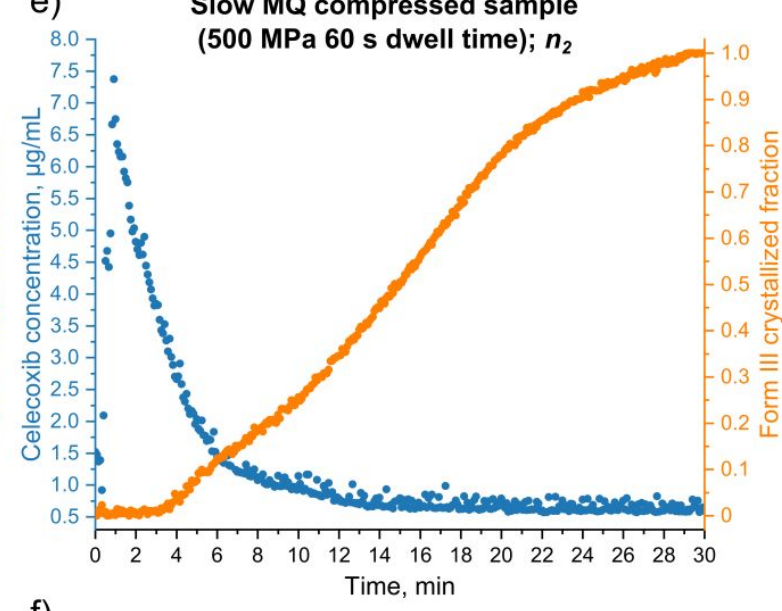

f)

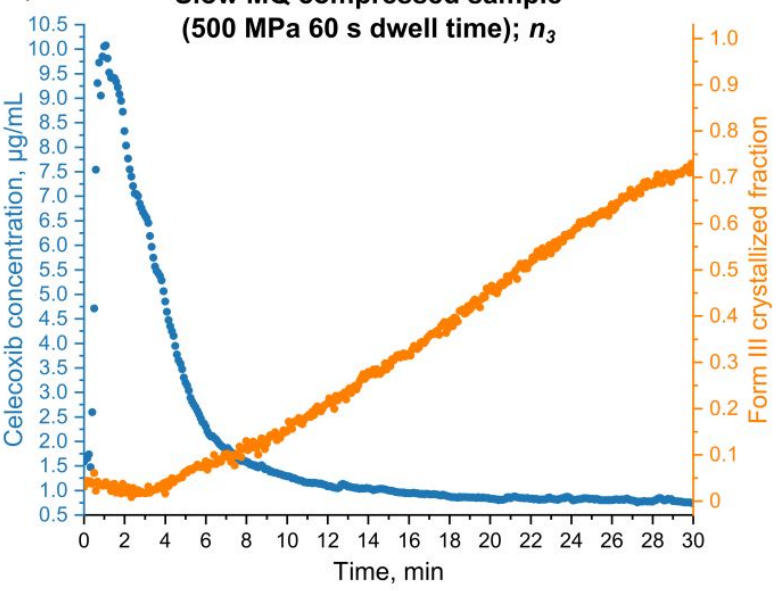

Figure S11. Dissolution profiles and MCR crystallization curves of component 2 (celecoxib form III) for slow melt-quenched (a-c) uncompressed and (d-f) compressed samples. Arrows denote artefacts due to the occasional air bubbles that were observed visually and distorted the LFR signal as well as manifested as a baseline in the UV/Vis spectra. Data from these regions were subtracted (not used) to determine the area under the dissolution curve. 

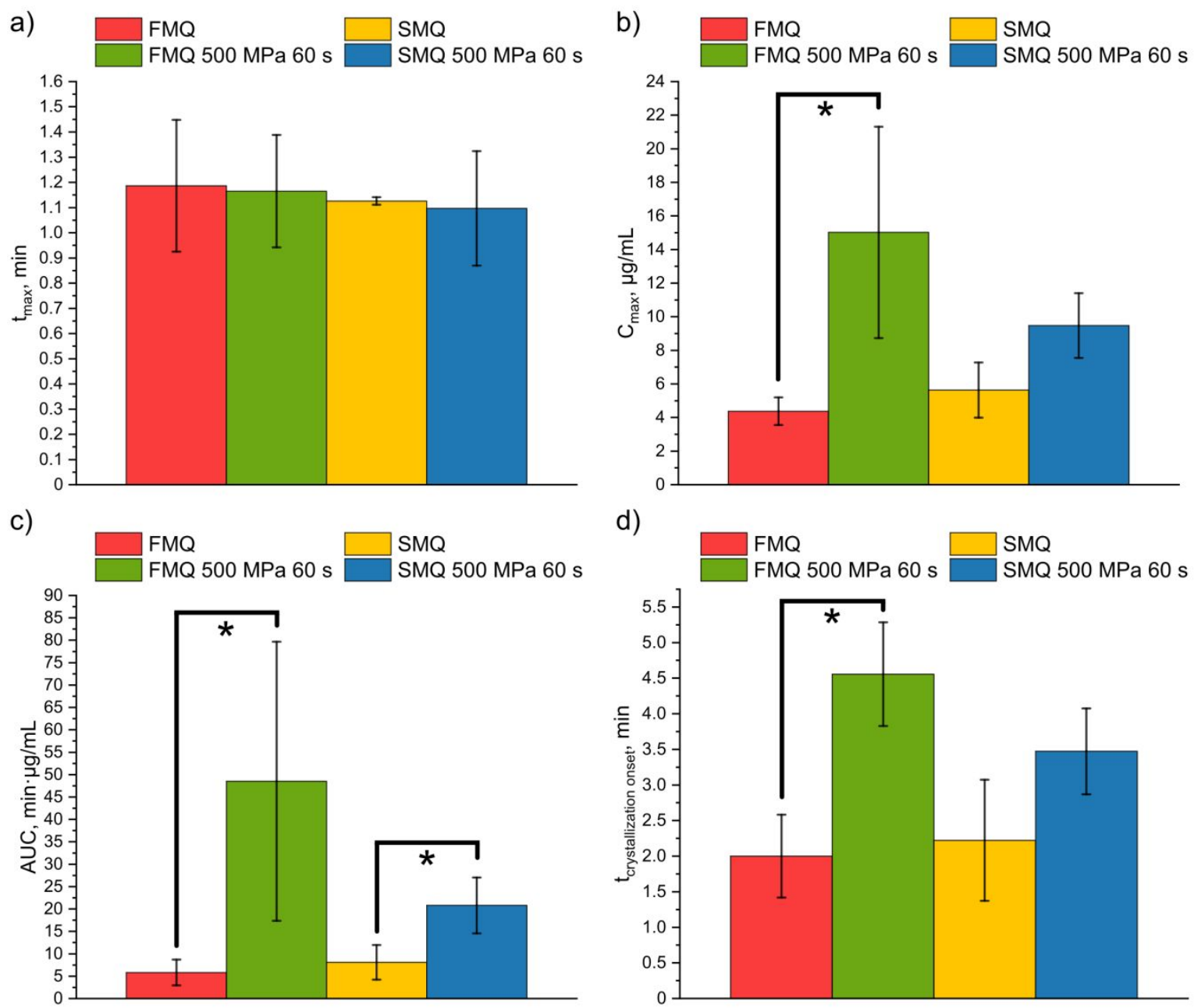

Figure S12. Statistical analysis of determined dissolution parameters for differently prepared and processed amorphous celecoxib samples (mean \pm standard deviation; $\mathrm{n}=3$ ). Asterisks $(*)$ denote a significant $(\mathrm{p}<0.05)$ difference between particular values.
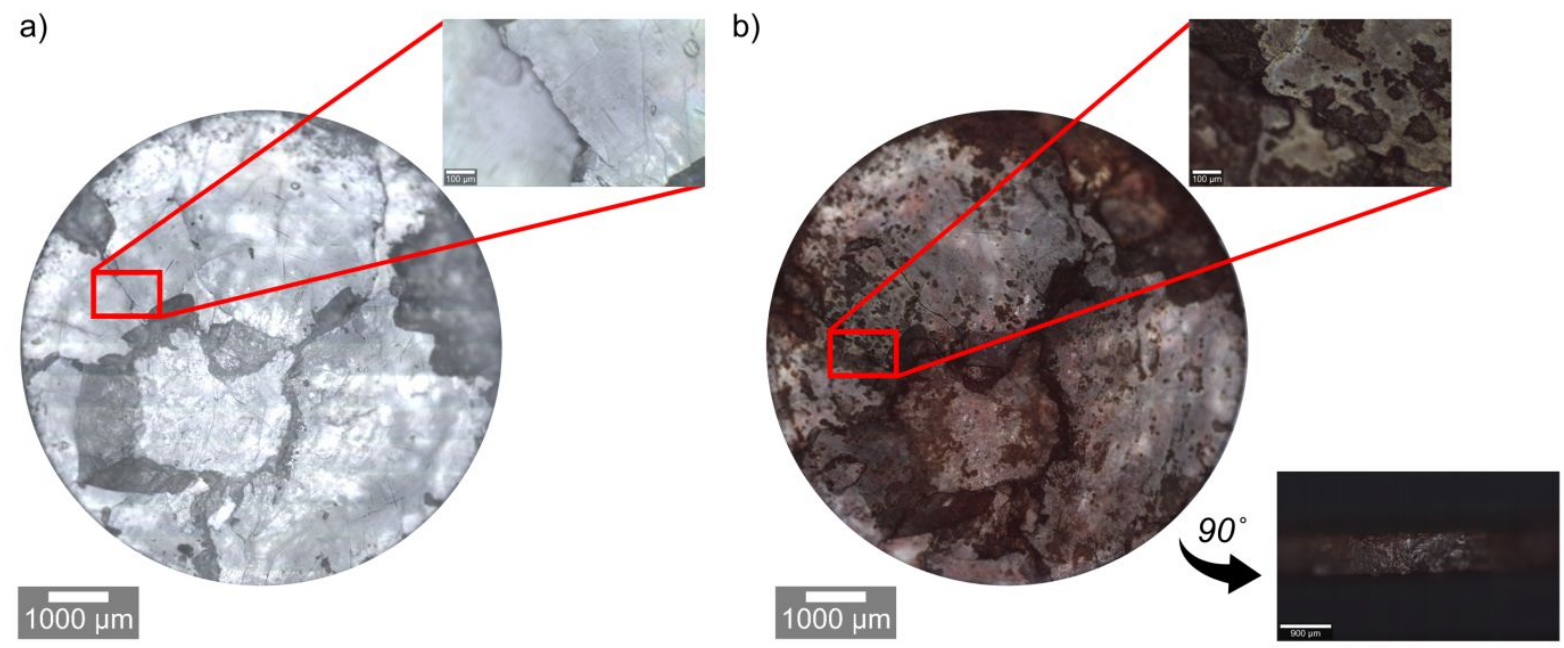

Figure S13. Digital images of a fast melt-quenched sample compressed at $500 \mathrm{MPa}$ with $60 \mathrm{~s}$ dwell time (a) before and (b) after the surface wetting experiments using an aqueous red dye solution. Highlighted areas denote the same regions, where fractures of different magnitude can be observed. 

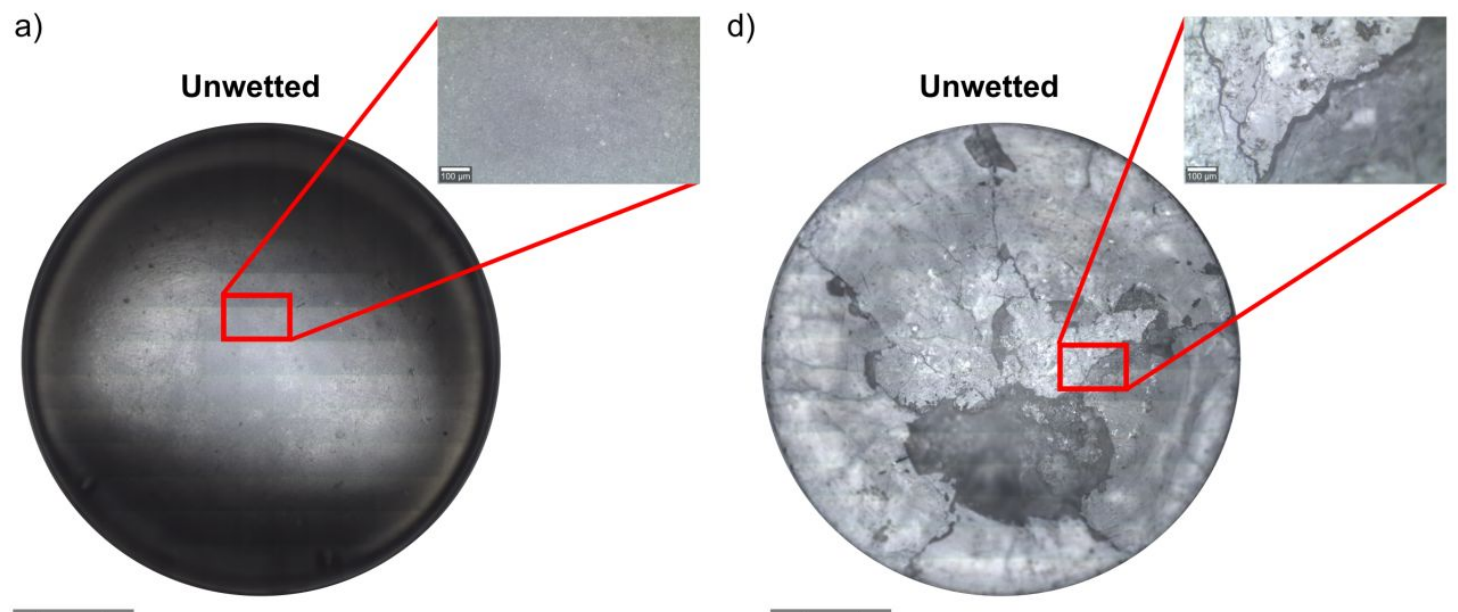

\section{$1000 \mu \mathrm{m}$}

b)

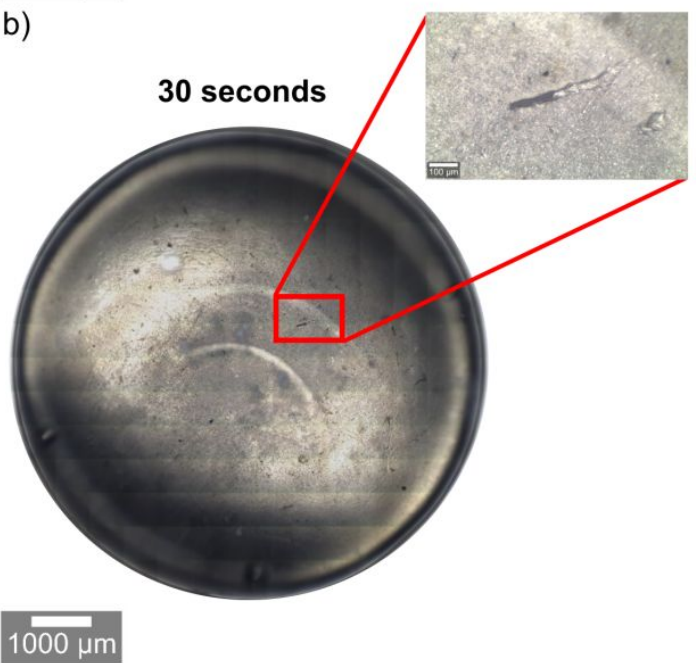

c)

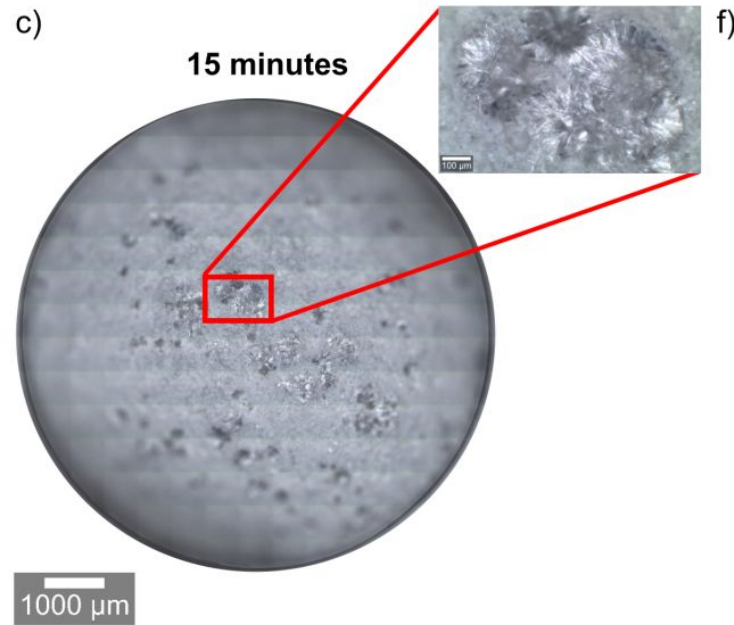

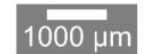

e)
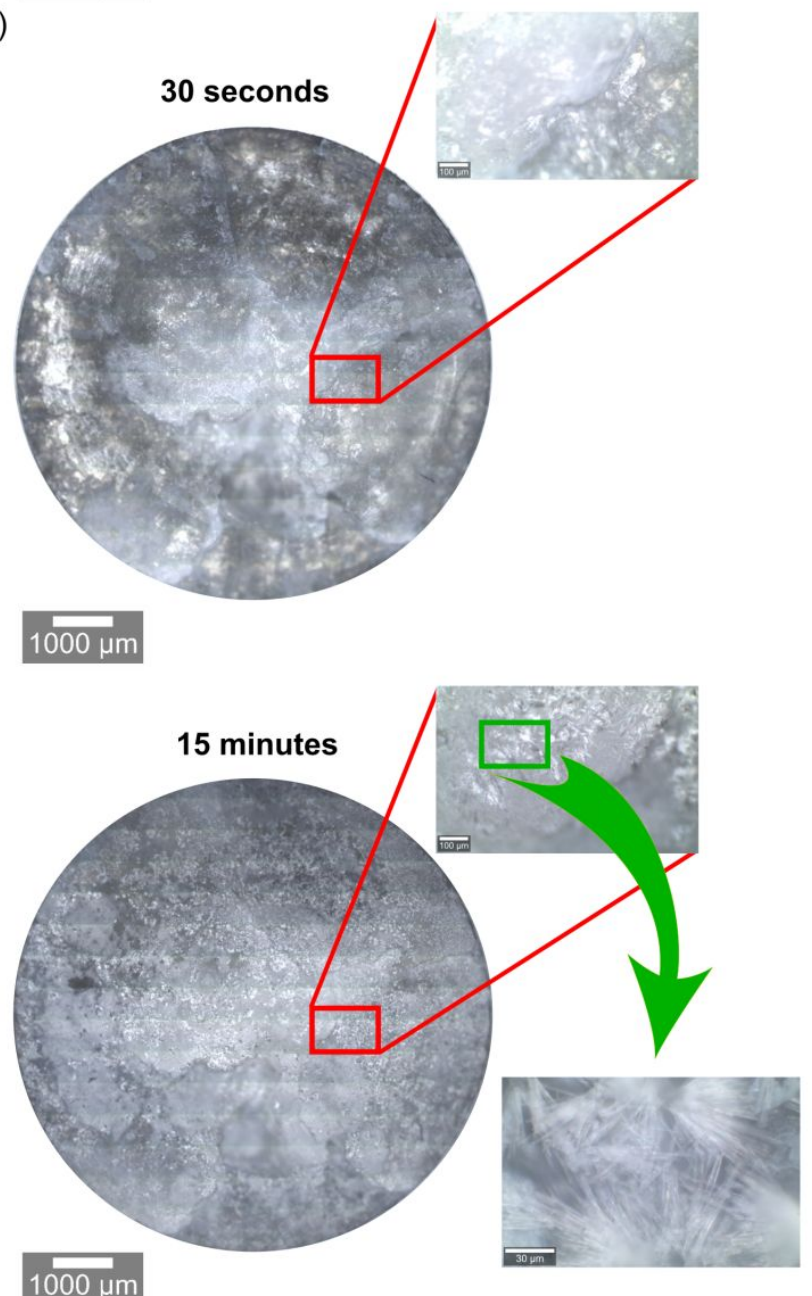

Figure S14. Digital images of fast melt-quenched samples: (a-c) uncompressed and (d-f) compressed at $500 \mathrm{MPa}$ with $60 \mathrm{~s}$ dwell time before and after the surface wetting experiments using $10 \mathrm{mM}$ trisodium phosphate solution. Highlighted areas denote the same regions, where interaction with the aqueous medium and progressive formation of celecoxib form III needle-shaped crystals can be observed. 